\title{
Ibuprofen-Glutathione Conjugate as Anti-inflammatory and Anti-apoptotic Agent in Rat Brain Infused with $\beta$ Amyloid (1-40)
}

\author{
Zara $\mathbf{S}^{1^{*}}$, De Colli $\mathbf{M}^{1}$, Sozio $\mathbf{P}^{1}$, Cacciatore $\mathbf{I}^{1}$, Bosco $\mathrm{D}^{2}$, Di Stefano $\mathbf{A}^{1}$, Nasuti $\mathbf{C}^{3}$ and Cataldi $\mathbf{A}^{1}$ \\ ${ }^{1}$ Dipartimento di Farmacia, Università G. d'Annunzio, Chieti-Pescara, Italy \\ ${ }^{2}$ Istituto di Genetica Molecolare del CNR, Unità di Chieti, Italy \\ ${ }^{3}$ Dipartimento di Medicina Sperimentale e Sanità Pubblica, Università di Camerino, Camerino (MC), Italy
}

*Corresponding author: Susi Zara, Dipartimento di Farmacia, Università G. d'Annunzio, Via dei Vestini, 31, 66100, Chieti, Italy, Tel: +39-0871-3554507; Fax: +39-0871-3554507; E-mail: s.zara@unich.it

Rec date: Feb 28, 2014, Acc date: May 26, 2014, Pub date: May 28, 2014

Copyright: (c) 2014 Zara S, et al. This is an open-access article distributed under the terms of the Creative Commons Attribution License, which permits unrestricted use, distribution, and reproduction in any medium, provided the original author and source are credited.

\begin{abstract}
Background: To date it is proved that Alzheimer's disease (AD) is characterized by a multifactorial etiology which comprises mitochondrial dysfunction, energy depletion, inflammation, and oxidative stress associated with glutathione depletion. All these factors are known to be impacted by beta amyloid protein (A $\beta$ ), which is responsible for the activation of amyloidogenic cascade. In the present work a rat intracerebroventricular $A \beta(1-40)$ infusion model of early $A D$ was employed to investigate the effects of lbuprofen-Glutathione (IBU-GSH) conjugate on morphological modifications, $A \beta$ plaque formation, apoptosis, learning, and memory performance.
\end{abstract}

Methods: Water maze test was used to evaluate drug administration effects on spatial reference memory, immunohistochemistry was carried out to determine $A \beta 1-40$, iNOS and caspase-3 expression; semithin sections and ultrastructural analyses, by means of light and transmission electron microscopy, respectively, were realized to evaluate samples morphology; TUNEL analysis to identify apoptotic cells.

Results and Conclusion: Results showed that in the $A \beta+I B U-G S H$ conjugate treated group, long-term memory consolidation at day 12 was improved, while learning appeared slower respect to control. In $A \beta$-infused rats, a higher number of $A \beta$ plaques, disorganized pyramidal pyknotic cells, apoptotic cells containing fragmented or swollen mitochondria, dilated blood vessels, and a low number of oligodendrocytes along with the high expression of inducible Nitric Oxide Synthase (iNOS) and caspase-3 were put in evidence. The inflammatory state seemed to be reversed by IBU-GSH treatment, as evidenced by a lower number of A $\beta$ plaques and pyknotic cells, and reorganized neurons containing normal mitochondria; despite this, persistent dilated blood vessels, decreased iNOS expression, lower percentage of apoptosis, and weak caspase-3 levels were observed. Thus mitochondria involvement in the AD inflammatory state is here strongly suggested and neuro-protective and anti-apoptotic IBU-GSH conjugate effect could be useful to reduce the AD inflammatory state.

Keywords: Alzheimer's disease; Apoptosis; Ultrastructural modifications; Ibuprofen-Glutathione conjugate; Oxidative stress; Spatial reference memory

\section{Abbreviations}

$\mathrm{AD}$ : Alzheimer's disease; $\mathrm{A} \beta$ : beta amyloid protein; IBU-GSH: Ibuprofen-Glutathione; iNOS: inducible Nitric Oxide Synthase; GSH: Glutathione; HNE: 4-hydroxynonenal; IL: interleukin; IBU: ibuprofen; NSAIDS: non-steroidal anti-inflammatory drug

\section{Introduction}

Alzheimer's disease (AD) is the most common form of dementia, associated with cardinal symptoms such as progressive memory loss due to the degeneration of neurons and synapses in the cerebral cortex and subcortical regions of the brain [1,2]. Neuropathologically, AD is characterized by the extracellular deposition of $\beta$-amyloid (A $\beta$ ) peptides, neurofibrillary tangle formation, chronic inflammatory response and oxidative damage [3]. The pathogenic cascade that leads to neurodegeneration in $\mathrm{AD}$ brain results in the production of $\mathrm{A} \beta$ - associated free radicals, oxidative stress, and alterations to Glutathione (GSH) metabolism [4]. In this context, studies by Gu et al. [5] reported that GSH levels are depressed in $\mathrm{AD}$ cingulated cortex and $\mathrm{AD}$ substantia innominata, while Liu et al. [6] found these reduced levels only in red blood cells of male AD patients. It has been observed that GSH protects cultured neurons against oxidative damage resulting from $\beta$-peptide and 4-hydroxynonenal (HNE), a lipid peroxidation product that is increased in $\mathrm{AD}$ [7]. A significant decrease in $\mathrm{Cu}$ and significant increases in $\mathrm{Zn}$ and Fe were found in $\mathrm{AD}$ hippocampus and amygdala, while $\mathrm{Cu}, \mathrm{Fe}$, and $\mathrm{Zn}$ are elevated in senile plaques of $\mathrm{AD}$. These metal ions can catalyze free radical reactions and contribute to oxidative damage observed in AD brain [8]. GSH protects these areas through formation of metal complexes via non enzymatic reactions and may also be beneficial for normalizing the adverse effects of iron accumulation in the aging brain [9].

Moreover, $A \beta$ deposition is also involved in the initiation of the inflammatory damage, which consequently led to neuronal cell apoptosis evoking gene expression of several inflammatory cytokines such as monocyte chemoattractant protein-1, interleukin (IL)-1 $\beta$, and IL-6 in cultured human brain endothelial cells [10]. Regardless of the exact mechanism, the cytotoxicity of $A \beta$ has been definitively linked to 
its aggregation and to the disruption of cell membranes by $\mathrm{AD}$ [11]. The dependence on gangliosides in the membrane disruption process corroborates previous results in that they clearly influence an alternative pathway for $A \beta$ aggregation. $A \beta$ polymerization in the presence of gangliosides generates structurally distinct aggregates; however, specific morphological features of these aggregates have yet to be determined [12]. Structural models have been constructed for the final amyloid product of aggregation. Although individual studies have probed the conformational preferences of the $A \beta(1-40)$ monomer, the high-resolution structure of $\mathrm{A} \beta(1-40)$ at $15^{\circ} \mathrm{C}$ at $\mathrm{pH} 7.3$ with $50 \mathrm{mM}$ $\mathrm{NaCl}$ has been solved by Vivekanandan et al. [13] suggesting that in this condition $\mathrm{A} \beta$ (1-40)adopts a folded conformation notably different from that seen in most previous NMR experiments. Moreover, molecular dynamics simulations showed that the A $\beta$ (1-40) monomer transiently binds to the $\mathrm{A} \beta$ (1-40) oligomer by non-native contacts with the side chains before being incorporated into the fiber through native contacts with the peptide backbone [14]. Combining 19F NMR with other spectroscopic techniques, more detailed information on the secondary structure of intermediates involved in amyloid formation could be obtained [15].

Agents with anti-inflammatory activities might potentially protect neurons against $A \beta$-induced neurotoxicity and enhance neuronal cell survival. For many years ibuprofen (IBU) has been considered the best non-steroidal anti-inflammatory drug (NSAID) for the treatment of $\mathrm{AD}$, as it specifically reduces pro-amyloidogenic al-antichymotrypsin mediated by reduction of interleukin-1 $\beta$ [16]; furthermore, it seems to prevent the development of the disease, as demonstrated by both epidemiological and clinical studies [17, 18]. Data from in vivo experiments demonstrated that IBU impacts amyloidogenesis and chronic inflammation [19], even if not all studies found an apparent protective effect of non-selective NSAIDs [20].

The rational structure-based design strategy can generate small molecules that can be target and modulate the multiple $\mathrm{AD}$ pathological factors [21]. Oxidative stress, metal ion dyshomeostasis, neuroinflammation, and $A \beta$ aggregation that are strictly connected with the onset of $\mathrm{AD}$, constitute a relevant therapeutical targets to address multifunctional ligand [21-25]. In our previous study, to improve the performance of the therapeutic treatment of $\mathrm{AD}, \mathrm{IBU}$ and GSH have been covalently joined via an amide bond to enhance their brain availability and administered in a chronic treatment to $A \beta(1-40)$-infused $A D$ rat brain model [26-28]. Results emerging from that study indicated that IBU-GSH possessed good in vitro physicochemical and antioxidant properties; it exhibited good stability toward enzymatic activity in human plasma and, like GSH, displayed in vitro free radical scavenging activity in a time and concentrationdependent manner [26]. Such compound might allow targeted delivery of IBU and GSH directly to neurons.

The aim of this work was to go deeper in the investigation of GSHIBU on morphological and ultrastructural modifications, $A \beta$ plaque number, inflammatory inducible Nitric Oxide Synthase (iNOS) protein and caspase-3 protein expression, and apoptosis rate occurrence in parallel to learning and memory performance.

\section{Materials and Methods}

\section{Animals}

Male Wistar rats ( $\mathrm{n}=24)$ (Harlan, UD, Italy), weighing 200-225 g at the beginning of the experiments, were used. The animals were individually housed in a single room on a $12 \mathrm{~h}$ light/dark cycle (lights off at 7:00 AM.) at constant temperature $\left(20-22^{\circ} \mathrm{C}\right)$ and humidity (45-55\%). Rats were offered food pellets (4RF; Mucedola, Settimo Milanese, Italy) and tap water ad libitum and were handled once a day for 5 min during the first week after arrival. Each animal was weighted weekly throughout the experimental period. All procedures were conducted in adherence to the European Community Council Directive for Care and Use of Laboratory Animals.

\section{Drug preparation}

IBU-GSH conjugate was synthesized and fully characterized as previously reported by us [26]. A $\beta$ (1-40) was prepared as previously described $[27,29]$ to achieve a final concentration of $0.023 \mathrm{nmol} / \mu \mathrm{L}$ through progressive dilutions starting from $1 \mathrm{mM}$. IBU-GSH conjugate was solubilised in sterile saline solution containing $2 \%(\mathrm{v} / \mathrm{v})$ DMSO and daily administered subcutaneously (s.c.) for 28 days at a dose of $10 \mathrm{mg} / \mathrm{kg}$ in a volume of $250 \mu \mathrm{L} / \mathrm{kg}$. A vehicle solution, prepared with sterile saline solution containing $2 \%(\mathrm{v} / \mathrm{v}) \mathrm{DMSO}$, was also administered subcutaneously for 28 days at a dose volume of 250 $\mu \mathrm{L} / \mathrm{kg}$.

\section{Animals treatment}

After anaesthesia with $10 \mathrm{mg} / \mathrm{kg}$ of a mixture of zolazepam and tiletamine (Zoletil 100, Italmed, Italy) by intraperitoneal injection, a stainless steel cannula was implanted in the lateral cerebroventricle of the animal using a stereotaxic instrument: anteroposterior, 1.0; lateral, 1.8. The $A \beta(1-40)$ solution was injected by intracerebroventricular (i.c.v.) infusion by an osmotic pump (Alzet, model 2004, Charles River, Italy) for 28 days. The concentration of $A \beta$ (1-40) in the osmotic pump was $23 \mu \mathrm{M}$ [30]. The animals were divided in three groups $(n=8$ rats): a control group, an $A \beta$-treated group, and an $A \beta+I B U-G S H$ conjugate-treated group. The first group continuously received the vehicle infused into the lateral ventricle by osmotic pump for 28 days; contemporaneously, vehicle was injected daily s.c. The second group constantly received $\mathrm{A} \beta$ (1-40) infused into the lateral ventricle for 28 days; vehicle was injected daily s.c. The third group continuously received $A \beta$ (1-40) infused into the lateral ventricle for 28 days and simultaneously IBU-GSH conjugate was injected daily s.c.

\section{Water maze test}

To assess the effect on the impairment of learning abilities in $A \beta$ infused $\mathrm{AD}$ rat model, rats were trained in a standard Morris water maze task one month after treatment with IBU-GSH [26]. Training consisted of four trials per day for five consecutive days and the intertrial interval was $30 \mathrm{~s}$. Each trial was stopped when the rat reached the hidden platform or when 90 s elapsed.

On day 6 (i.e., 24 hrs following the last day of training) a probe trial was performed in which the platform was removed from the pool to measure the time spent in the target quadrant where the platform was located during the training. This assessment provided an evaluation of strength and accuracy of the memory of the previous platform location. On day 12 (i.e., 6 days post-training) a second probe trial was performed in which the platform was removed. Both probe trials provided an estimate of the long-term spatial memory consolidation. The time elapsed in the probe test was $60 \mathrm{~s}$. 
Page 3 of 8

\section{Samples withdrawal}

Rats were killed by $\mathrm{CO}_{2}$, brains were rapidly removed, then divided in the two hemispheres, and each half randomly processed for light and electron microscopy. The whole hemispheres were (average size: 2 $\mathrm{cm}$ height, $0.5 \mathrm{~cm}$ width and $0.5 \mathrm{~cm}$ depth) fixed in $10 \%$ phosphatebuffered formalin at $\mathrm{pH} 7.0$ for $48 \mathrm{~h}$ and dehydrated through ascending concentrations of alcohol and xylene, and then paraffin embedded. For electron microscopy rat cortex was isolated, immediately put into fixative solution (2.5\% glutaraldehyde in $0.1 \mathrm{M}$ phosphate buffer at $\mathrm{pH} 7.6$ ), sectioned (average size: $0.3 \mathrm{~cm}$ width, 0.3 $\mathrm{cm}$ height, and $0.3 \mathrm{~cm}$ depth) and maintained into fixative solution for $4 \mathrm{hrs}$ at $4^{\circ} \mathrm{C}$. After washing in the same buffer, samples were post-fixed in $1 \% \mathrm{OsO}_{4}$ in phosphate buffer for $1 \mathrm{hrs}$ at $4{ }^{\circ} \mathrm{C}$, acetone dehydrated and Epon embedded followed by polymerization for 3 days at $60^{\circ} \mathrm{C}$.

\section{Transmission Electron Microscopy}

Ultra-thin cortex sections (100 nm) were cut and mounted on 300 mesh nickel grids. Uranyl acetate and lead citrate counterstained grids were observed using transmission electron microscopy (Zeiss 109). Cerebral cortex semi-thin sections $(1 \mu \mathrm{m})$ were stained with $1 \%$ toluidine blue and observed at light microscopy.

\section{Morphological and immunohistochemical analyses}

Samples were then defatted with xylene and alcohol with progressively lower concentrations, and $5 \mu \mathrm{m}$ thick frontal section were processed for immunohistochemical and TUNEL analyses. DNA strand breaks, yielded during apoptosis, can be identified by labeling free $3^{\prime}-\mathrm{OH}$ termini with modified nucleotides in an enzymatic reaction. All steps were carried out with FragEL DNA fragmentation Detection Kit according to the manufacturer's instructions (Calbiochem Merck, Cambridge, MA, USA). After two rinses in PBS, slides were dehydrated, mounted by using a permanent media, and analyzed by light microscope (Leica Cambridge Ltd, Cambridge, UK). Five slides from each sample were assessed; apoptotic cells count was performed on ten fields per slide. Negative control was performed by omitting the incubation in the presence of the enzymatic mixture, positive control (not shown) was performed by treating one slide with DNAse I.

In order to detect $A \beta$ (1-40), iNOS, and cleaved caspase- 3 proteins, immunohistochemistry was performed on $5 \mu \mathrm{m}$ thick sections by means of Ultravision LP Detection System HRP Polymer \& DAB Plus Chromogen (Lab Vision Thermo, CA, USA). Slides were first covered with $10 \mathrm{mM}$ sodium citrate buffer at $\mathrm{pH} 6.0$, heated at $95^{\circ} \mathrm{C}$ for 5 minutes to unmask antigens, and then incubated in the presence of rabbit anti-cleaved caspase-3 monoclonal antibody (Cell Signalling Technology Inc, MA, USA), rabbit anti-iNOS polyclonal antibody (Santa Cruz Biotechnology, Santa Cruz CA) and mouse anti-A $\beta(1-40)$ monoclonal antibody (Alpha Diagnostic International, TX, USA). Negative controls were performed by omitting primary antibodies, according to the manufacturer's instructions. Samples were then observed by means of light microscopy Leica DM 4000 (Leica Cambridge Ltd, Cambridge, UK) equipped with a Leica DFC 320 camera (Leica Cambridge Ltd, Cambridge, UK) for computerized images.

\section{Computerized Morphometry measurements and Image Analysis}

To evaluate $A \beta$ expression, computerized images derived from immunohistochemical stained sections were analyzed by QWin Plus 3.5 software (Leica Cambridge Ltd, Cambridge, UK). Image analysis of $A \beta$ expression was performed through quantification of thresholded area for immunohistochemical brown-colored $A \beta$ on ten fields for each slide (five) per each of sample (three), chosen through systematic and uniformly random sampling of the fields of vision through a predefined XY step, at 40 magnification by Leica Qwin Plus 3.5 Software. Image analysis of cleaved caspase-3 and iNOS expression was performed through quantification of positive cells out of total of 100 cells, at 40 magnification by Leica Qwin Plus 3.5 Software. Five slides per sample were examined. QWin Plus 3.5 assessments were logged to Microsoft Excel and processed for Standard Deviations and Histograms.

\section{Statistics}

Statistical analysis was performed using the analysis of variance (ANOVA) and results expressed as mean \pm SD. Appropriate post-hoc analysis was carried out using the Newman-Keuls test. Values of $\mathrm{p}$ $<0.05$ were considered statistically significant.

\section{Results}

In this paper it was investigated whether IBU-GSH conjugate (Figure 1) could improve learning and memory impairment in an infused $A \beta$ (1-40) rat model. It was found that the time spent to reach the platform by $A \beta+$ IBU-GSH treated group was lower at the second and third day of training respect to the time spent by the $A \beta$ treated group. However, since the values were not statistically different $(\mathrm{P}=0.05)$, it was assumed that both groups, treated with $\mathrm{A} \beta$ and $\mathrm{A} \beta$ + IBU-GSH, respectively, show the same performance in learning (Figure 2). Concerning the long-term memory consolidation, all groups at the probe tests 24 hrs (day 6) after training do not show any differences. Furthermore, one week after training (day 12), the performance of $A \beta+\mathrm{IBU}-\mathrm{GSH}$ treated group is improved, compared to $A \beta$-treated group $(\mathrm{p}<0.05)$, as shown in Table 1 . Thus, IBU-GSH treatment seems to be effective in slowing down the $A \beta$ plaques deposition by preserving long-term memory in treated rats. Another explanation, could be that the animals treated with IBU+GSH conjugate show less extinction than the other groups.

\begin{tabular}{|l|l|l|l|}
\hline \multirow{2}{*}{ Day of probe trial } & \multicolumn{3}{|l|}{ Time spent in the target quadrant (s) } \\
\cline { 2 - 4 } & control & $A \beta$ & $A \beta+$ IBU-GSH \\
\hline 6 & $35 \pm 1$ & $33 \pm 1$ & $37 \pm 2$ \\
\hline 12 & $22 \pm 2$ & $18 \pm 1$ & $34 \pm 1 \mathrm{a}$ \\
\hline
\end{tabular}

Table 1: Effects of drug administration on spatial reference memory in a Morris water maze. Performance during probe trial was expressed as the mean $( \pm S D)$ of time spent in the target quadrant where the platform had been during five consecutive days of training from control, $A \beta$, and $A \beta+I B U-G S H$ treated groups on day 6 and on day 12 . a: $p<0.05 \mathrm{~A} \beta+\mathrm{IBU}-\mathrm{GSH}$ vs $\mathrm{A} \beta$. 
<smiles>CC(=O)CNC(=O)[C@H](CS)NC(=O)CC[C@H](NC(=O)C(C)c1ccc(CC(C)C)cc1)C(C)=O</smiles>

Figure 1: Chemical structure of IBU-GSH conjugate

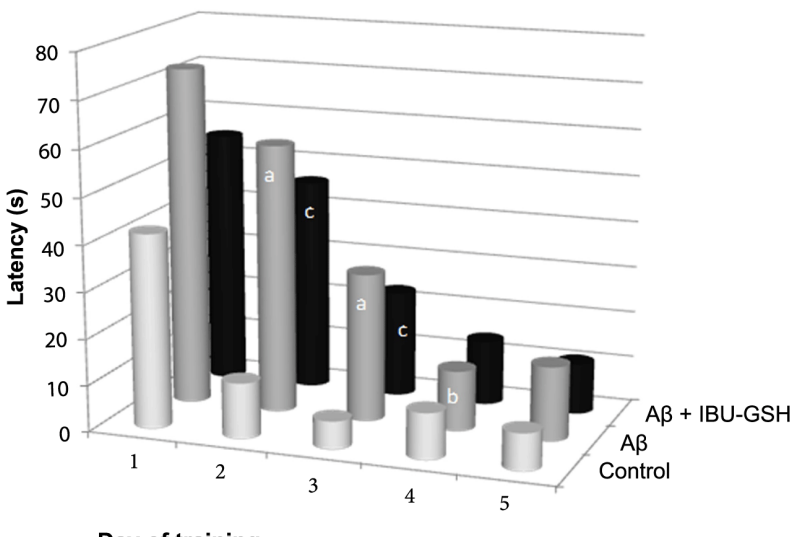

Day of training

Figure 2: Effects of drug administration on spatial reference memory in a Morris water maze. Performance during acquisition was expressed as the mean latency to find a submerged platform from control, $A \beta$ and $A \beta+\mathrm{IBU}-\mathrm{GSH}$ conjugate during five consecutive days of training (four trials per day). Control: untreated sample. SE are less than $5 \%$ of mean values. a: $\mathrm{p}<0.01$ : - day $2 \mathrm{~A} \beta$ vs control; - day $3 \mathrm{~A} \beta$ vs control. b: $p<0.05$ : day $4 \mathrm{~A} \beta$ vs control. c: $p$ $<0.05$ : - day $2 \mathrm{~A} \beta+\mathrm{IBU}-\mathrm{GSH}$ vs control;- day $3 \mathrm{~A} \beta+\mathrm{IBU}-\mathrm{GSH}$ vs control A $\beta$

To verify $A D$ induction after $A \beta(1-40)$ infusion, cortex sections were processed for $A \beta(1-40)$ immunohistochemical analysis finding a lower number of $A \beta$ plaques and protein expression in $A \beta$-infused cerebral cortex of rats treated with IBU-GSH respect to the $A \beta$-infused ones (Figure $3 \mathrm{~A}$ and $3 \mathrm{~B}$ ). Also morphological modifications were evaluated through a preliminary analysis performed at light microscope by means of toluidine blue stained semithin sections. This analysis discloses the control sample showing six well-organized and conserved cells layers, connected by oligodendrocytes. On the other hand, $\mathrm{A} \beta$-infused rat cerebral cortex shows amyloid plaques, disorganized cells layers with collapsed pyramidal pyknotic cells likely apoptotic cells and a lower number of oligodendrocytes - while IBU-GSH treated cerebral cortex show a lower number of pyknotic cells along with reorganized neurons (Figure 4A). These findings led us to better investigate the morphological situation focusing attention on mitochondria through an electron microscopy analysis, which reveals a large number of well-preserved mitochondria in control sample, fragmented or swollen mitochondria and Golgi apparatus in $\mathrm{A} \beta$-infused cortex, while mitochondria with normal structure and regular cristae are found in IBU-GSH treated cerebral cortex (Figure 4B).

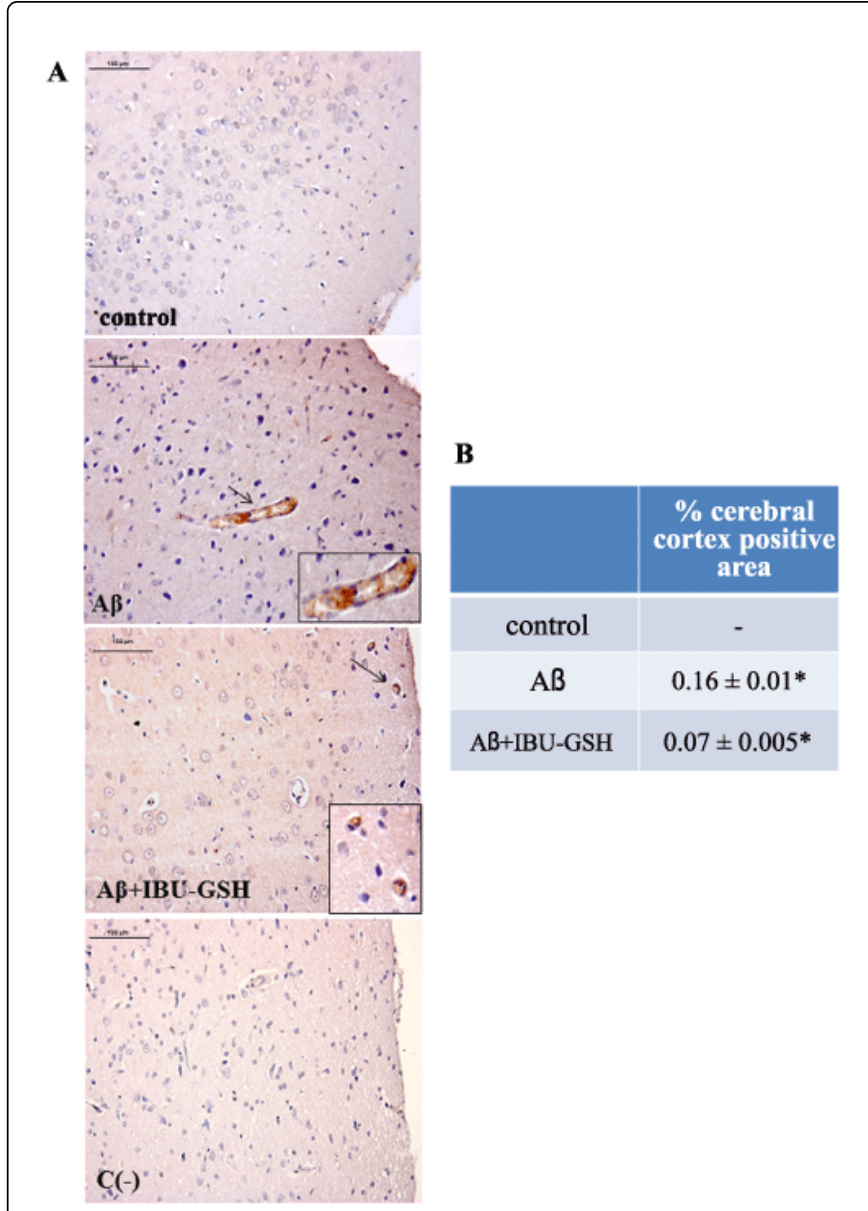

Figure 3: A: Immunohistochemical detection of $A \beta$ (1-40) in rat cerebral cortex in different experimental conditions. Scale bar size $100 \mu \mathrm{m}$. Control: untreated sample; $A \beta$ : $A \beta$-injected cerebral cortex; $A \beta+\mathrm{IBU}-\mathrm{GSH}: \mathrm{A} \beta$-injected cerebral cortex+IBU-GSH conjugate; $C(-)$ : negative control; arrows indicate $A \beta(1-40)$ plaques, inserts show $A \beta(1-40)$ plaques at higher magnification in $A \beta$ and $\mathrm{A} \beta+\mathrm{IBU}-\mathrm{GSH}$ samples. B: Densitometric analysis of $\mathrm{A} \beta$ (1-40) positive area, expressed as $\%$ of positive area \pm SD. Means are \pm SD of three different consistent experiments. * $A \beta+\mathrm{IBU}-\mathrm{GSH}$ conjugate vs $A \beta: p<0.05$

As the cellular suffering evidenced by the morphological analysis could be due to an inflammatory state, the expression of iNOS-a key factor in the inflammation onset-was evaluated through immunohistochemical analysis. iNOS level appears significantly higher in $\mathrm{A} \beta$-infused cortex respect to IBU-GSH treated cerebral cortex (Figure 5A and 5B).

Finally, the apoptotic event occurrence supposed after the morphological evaluation, was investigated through both TUNEL analysis and pro-apoptotic caspase-3 expression, disclosing a significantly lower percentage of apoptotic nuclei in $A \beta$-infused rat cerebral cortex treated with IBU-GSH compared to the A $\beta$-infused one (Figure 6A and 6B). The reduction of apoptotic cell percentage is matched to a weak pro-apoptotic caspase-3 level in the same experimental conditions (Figure 7A and 7B). 
Citation: Zara S, De Colli M, Sozio P, Cacciatore I, Bosco D (2014) Ibuprofen-Glutathione Conjugate as Anti-inflammatory and Anti-apoptotic Agent in Rat Brain Infused with $\beta$ Amyloid (1-40). J Cytol Histol 5: 249. doi:10.4172/2157-7099.1000249

Page 5 of 8

$\mathbf{A}$
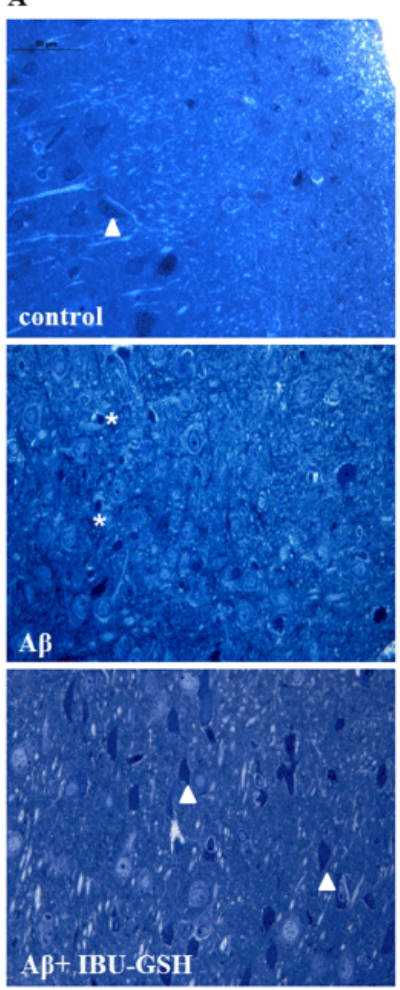

B

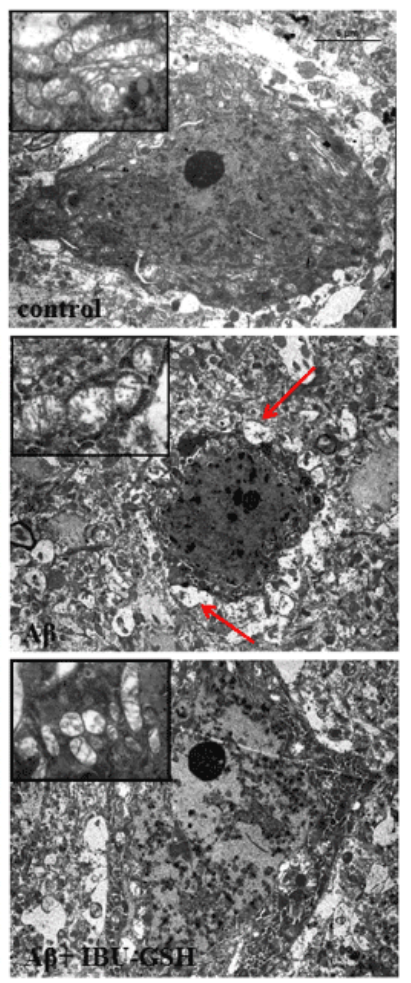

Figure 4: A: Toluidine blue stained semi-thin rat cerebral cortex sections in different experimental conditions. Scale bar size $50 \mu \mathrm{m}$. B: Transmission electron microscopy analysis of rat cerebral cortex in different experimental conditions. Scale bar size $5 \mu \mathrm{m}$. Control: untreated sample; $A \beta$ : $A \beta$-injected cerebral cortex; $A \beta+I B U-G S H$ : $A \beta$-injected cerebral cortex+IBU-GSH conjugate. Asterisks indicate collapsed pyramidal pyknotic cells, arrows indicate damaged mitochondria in $A \beta$ sample, arrow heads indicate normal neurons. Inserts show higher magnification of regular and not interrupted mitochondrial cristae in control sample, an evident mitochondria enlargement and cristae interruption in $A \beta$ sample, and a restoration of basal situation is detectable in $\mathrm{A} \beta+\mathrm{IBU}-\mathrm{GSH}$ sample

\section{Discussion}

This report describes the in vivo effects exerted by IBU-GSH conjugate on morphological modifications, $A \beta$ plaque formation, iNOS protein expression, and apoptosis rate occurrence in parallel to learning and memory performance in $A \beta(1-40)$-infused rat cerebral cortex, which represents a model of AD. Although the etiology of AD has not been exhaustively elucidated yet, mitochondrial dysfunction, metal-ion dysregulation, and oxidative stress have been linked to the progressive neurological decline associated with this neurodegenerative disorder [3,31-33]. In oxidative stress conditions, GSH is able to detoxify various oxidants by directly scavenging free radicals and acting as a coenzyme in GSH-peroxidase catalysed reactions and/or chelating agent $[6,23,34,35]$. Moreover, a recent renewed interest in non-steroidal anti-inflammatory drugs for $\mathrm{AD}$ treatment stems from findings suggesting that some NSAIDs (e.g.

Ibuprofen, Flurbiprofen) might influence other pathogenic features of $\mathrm{AD}$ such as oxidative damage $[18,36]$.

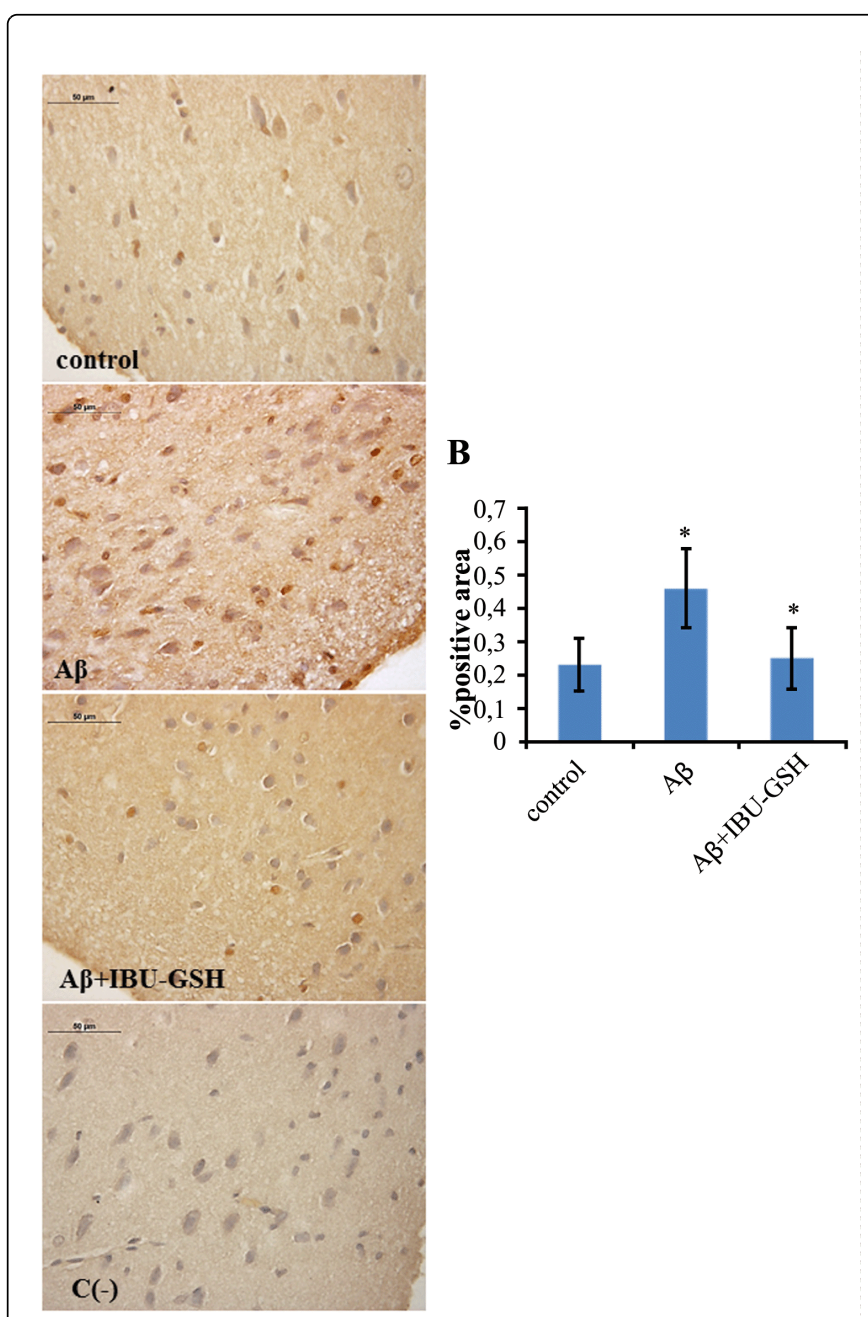

Figure 5: A: Immunohistochemical detection of iNOS in rat cerebral cortex. Scale bar size $50 \mu \mathrm{m}$. Control: untreated sample; $A \beta$ : $A \beta$-injected cerebral cortex; $A \beta+I B U-G S H: A \beta$-injected cerebral cortex+IBU-GSH conjugate; $\mathrm{C}(-)$ : negative control; $\mathrm{B}$ : Graphical representation of iNOS positive cells percentages. Values are means $\pm \mathrm{SD}$; ${ }^{*} \mathrm{~A} \beta+\mathrm{IBU}-\mathrm{GSH}$ conjugate vs $\mathrm{A} \beta: \mathrm{p}<0.05$

In this study the potential synergic antioxidant and antiinflammatory properties of IBU-GSH conjugate [26] in rat brains infused with $\mathrm{A} \beta$ (1-40), as a model of $\mathrm{AD}$, was investigated [37]. The animals developed $A \beta$ amyloid plaques and spatial memory deficits in a radial maze, as already described [27]. The $A \beta(1-40)$ was chosen for its higher ability to form amyloid fibrils in rats, and its neurodegenerative effect is more pronounced than $A \beta$ (1-42), as evidenced within the CA1 subfield of the hippocampus [38]. Furthermore, $A \beta(1-40)$ is more soluble than $A \beta$ (1-42): in fact, there is less likelihood that it precipitates in the osmotic pumps and/or in the tube connecting the pump to the ventricle. As previously reported [26], the free radical scavenging activity of IBU-GSH conjugate was evaluated evidencing a dose-dependent radical scavenging activity of the conjugate respect to IBU alone. 
Citation: Zara S, De Colli M, Sozio P, Cacciatore I, Bosco D (2014) Ibuprofen-Glutathione Conjugate as Anti-inflammatory and Anti-apoptotic Agent in Rat Brain Infused with $\beta$ Amyloid (1-40). J Cytol Histol 5: 249. doi:10.4172/2157-7099.1000249

Page 6 of 8

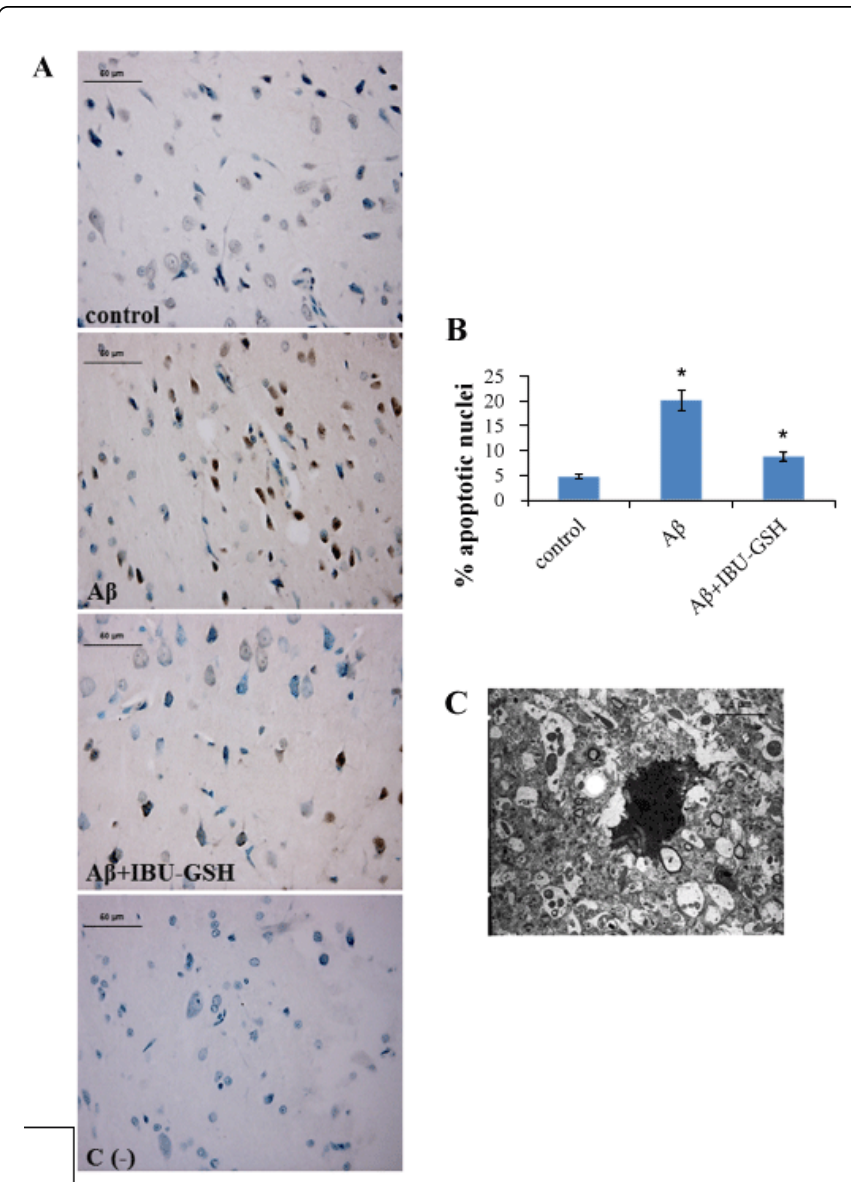

Figure 6: A: TUNEL analysis of rat cerebral cortex in different experimental conditions. Scale bar size $50 \mu \mathrm{m}$. Control: untreated sample; $A \beta$ : $A \beta$-injected cerebral cortex; $A \beta+I B U-G S H: A \beta-$ injected cerebral cortex+IBU-GSH conjugate; $\mathrm{C}(-)$ : negative control; B: Graphical representation of TUNEL analysis. Apoptotic cells were counted out of total of 100 cells by Leica Qwin Plus 3.5 Software. Percentages values are means $\pm \mathrm{SD}$; $A \beta+\mathrm{IBU}-\mathrm{GSH}$ conjugate vs $A \beta: p<0.05$; $C$ : Transmission electron microscopy analysis of an apoptotic cell. Scale bar size $5 \mu \mathrm{m}$

In particular, neuronal cells and blood vessels organization results modified in $\mathrm{AD}$ rat brain; mitochondria appear swollen and their number reduced, along with a significant increase in their size, maybe inducing an aspecific release of mitochondrial matrix components, including Cytochrome $c$ and apoptosis inducing factor 1 (Apaf-1), which can activate a cascade of changes which lead to apoptotic cell death in $\mathrm{AD}[28,39]$. Upon IBU-GSH conjugate treatment, neuronal cells appear reorganized and mitochondria show restoration of their normal structure and number along with a successful spatial long-term consolidation or longer time of extinction given 6 days after training (day 12) in a Morris water maze task. This treatment also reverses the A $\beta$-induced iNOS over-expression, strongly related to the spatial memory impairment, as already reported by Huang et al. [40]. The recruitment of healthy elongated mitochondria, upon antioxidant, anti-inflammatory, and neuroprotective IBU-GSH combined treatment, could be coupled to nerve terminals to supply ATP allowing a better function [41]. These results seem to be paralleled by the inhibition of the apoptotic route driven by caspase-3, due to IBU-GSH combined treatment even though, as suggested by Lamkanfi and Kanneganti [42], a role was also assigned to caspase-7 in the occurrence of the apoptotic event.

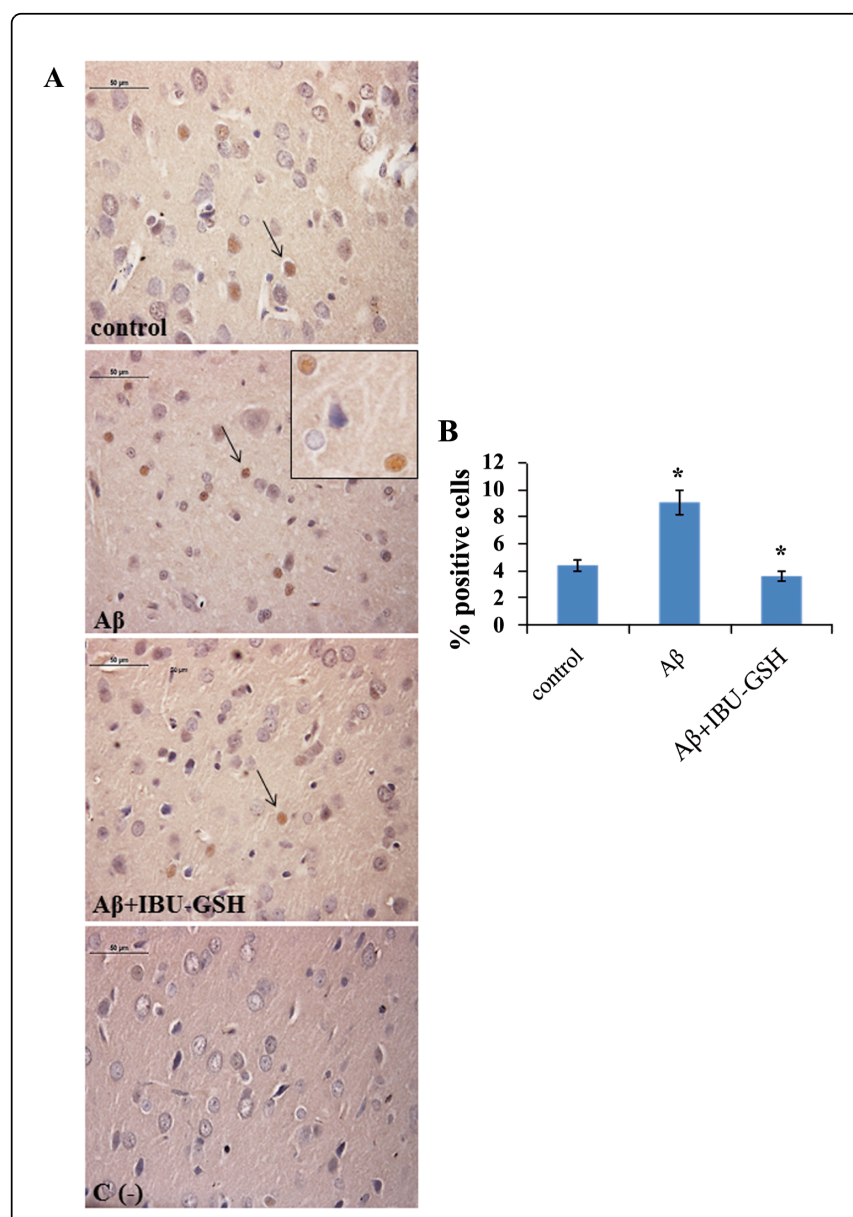

Figure 7: A: Immunohistochemical detection of caspase-3 in rat cerebral cortex in different experimental conditions. Scale bar size $50 \mu \mathrm{m}$. Control: untreated sample; $A \beta$ : $A \beta$-injected cerebral cortex; A $\beta+I B U-G S H: A \beta$-injected cerebral cortex+IBU-GSH conjugate; $C$ $(-)$ : negative control. Insert shows nuclear localization of cleaved caspase-3 (magnification 40x); B: Graphical representation of caspase- 3 positive cells percentages. Percentages values are means \pm $\mathrm{SD} ;{ }^{*} \mathrm{~A} \beta+\mathrm{IBU}-\mathrm{GSH}$ conjugate vs $\mathrm{A} \beta: \mathrm{p}<0.05$

In alignment with other reports [43,44], and together with other major cellular changes-such as $A \beta$ and amyloid cascade events, synaptic pathology, neuronal loss, and inflammatory responsesmitochondria involvement in the occurrence of $\mathrm{AD}$ and neuroprotective and anti-apoptotic functions of IBU-GSH conjugate are here further supported.

Compared to other drugs intended for AD therapy, GSH-IBU conjugate appears to be particularly promising because it acts as neuroprotective and anti-apoptotic agent causing a dramatic reduction in oxidative damage and amyloid deposition in a rat model of AD.

Although basic biophysical studies would be necessary to elucidate how IBU-GSH conjugate may interfere with $A \beta$ aggregation process, taken together, these results are of significance for prospective 
therapeutic application of our conjugate in neuropathological events associated with free radical damage, mitochondrial dysfunction, and apoptosis.

\section{Acknowledgements}

This work has been supported by MIUR 60\% 2011 Prof. A. Di Stefano, Prof. A. Cataldi, Dr. I. Cacciatore.

\section{References}

1. DeKosky ST (2002) [Neurobiology and molecular biology of Alzheimer's disease]. Rev Neurol 35: 752-760.

2. Drouet B, Pinçon-Raymond M, Chambaz J, Pillot T (2000) Molecular basis of Alzheimer's disease. Cell Mol Life Sci 57: 705-715.

3. Parihar MS, Hemnani T (2004) Alzheimer's disease pathogenesis and therapeutic interventions. J Clin Neurosci 11: 456-467.

4. Lee M, Cho T, Jantaratnotai N, Wang YT, McGeer E, et al. (2010) Depletion of GSH in glial cells induces neurotoxicity: relevance to aging and degenerative neurological diseases. FASEB J 24: 2533-2545.

5. Gu M, Owen AD, Toffa SE, Cooper JM, Dexter DT, et al. (1998) Mitochondrial function, GSH and iron in neurodegeneration and Lewy body diseases. J Neurol Sci 158: 24-29.

6. Liu H, Harrell LE, Shenvi S, Hagen T, Liu RM (2005) Gender differences in glutathione metabolism in Alzheimer's disease. J Neurosci Res 79: 861-867.

7. Mark RJ, Lovell MA, Markesbery WR, Uchida K, Mattson MP (1997) A role for 4-hydroxynonenal, an aldehydic product of lipid peroxidation, in disruption of ion homeostasis and neuronal death induced by amyloid beta-peptide. J Neurochem 68: 255-264.

8. Butterfield DA, Pocernich CB, Drake J (2002) Elevated glutathione as a therapeutic strategy in Alzheimer's disease. Drug Develop Res 56: 428-437.

9. Hammond CL, Lee TK, Ballatori N (2001) Novel roles for glutathione in gene expression, cell death, and membrane transport of organic solutes. J Hepatol 34: 946-954.

10. Yamamoto M, Kiyota T, Horiba M, Buescher JL, Walsh SM, et al. (2007) Interferon-gamma and tumor necrosis factor-alpha regulate amyloidbeta plaque deposition and beta-secretase expression in Swedish mutant APP transgenic mice. Am J Pathol 170: 680-692.

11. Sciacca MF, Kotler SA, Brender JR, Chen J, Lee DK, et al. (2012) Twostep mechanism of membrane disruption by $\mathrm{A}^{2}$ through membrane fragmentation and pore formation. Biophys J 103: 702-710.

12. Kotler SA1, Walsh P, Brender JR, Ramamoorthy A (2014) Differences between amyloid- $\hat{I}^{2}$ aggregation in solution and on the membrane: insights into elucidation of the mechanistic details of Alzheimer's disease. Chem Soc Rev .

13. Vivekanandan S, Brender JR, Lee SY, Ramamoorthy A (2011) A partially folded structure of amyloid-beta(1-40) in an aqueous environment. Biochem Biophys Res Commun 411:312-316.

14. Krishnamoorthy J, Brender JR, Vivekanandan S, Jahr N, Ramamoorthy A (2012) Side-chain dynamics reveals transient association of $\mathrm{A}^{2}(1-40)$ monomers with amyloid fibers. J Phys Chem B 116: 13618-13623.

15. Suzuki Y, Brender JR, Soper MT, Krishnamoorthy J, Zhou Y, et al. (2013) Resolution of oligomeric species during the aggregation of $\mathrm{AI}^{2} 1-40$ using (19)F NMR. Biochemistry 52: 1903-1912.

16. Morihara T, Teter B, Yang F, Lim GP, Boudinot S, et al. (2005) Ibuprofen suppresses interleukin-1beta induction of pro-amyloidogenic alpha1antichymotrypsin to ameliorate beta-amyloid (Abeta) pathology in Alzheimer's models. Neuropsychopharmacology 30: 1111-1120.

17. Vlad SC, Miller DR, Kowall NW, Felson DT (2008) Protective effects of NSAIDs on the development of Alzheimer disease. Neurology 70 : 1672-1677.

18. Pasqualetti P, Bonomini C, Dal Forno G, Paulon L, Sinforiani E, et al. (2009) A randomized controlled study on effects of ibuprofen on cognitive progression of Alzheimer's disease. Aging Clin Exp Res 21: 102-110.

19. Lim GP, Yang F, Chu T, Chen P, Beech W, et al. (2000) Ibuprofen suppresses plaque pathology and inflammation in a mouse model for Alzheimer's disease. J Neurosci 20: 5709-5714.

20. Sonnen JA, Larson EB, Walker RL, Haneuse S, Crane PK, et al. (2010) Nonsteroidal anti-inflammatory drugs are associated with increased neuritic plaques. Neurology 75: 1203-1210.

21. Lee S, Zheng X, Krishnamoorthy J, Savelieff MG, Park HM, et al. (2014) Rational design of a structural framework with potential use to develop chemical reagents that target and modulate multiple facets of Alzheimer's disease. J Am Chem Soc 136: 299-310.

22. Cacciatore I, Baldassarre L, Fornasari E, Cornacchia C, Di Stefano A et al. (2012) (R)-a-Lipoyl-glycyl-L-prolyl-L-glutamyl dimethyl ester codrug as a multifunctional agent with potential neuroprotective activities. Chem Med Chem 7: 2021-2029.

23. Cacciatore I, Cornacchia C, Fornasari E, Baldassarre L, Pinnen F et al. (2013) A Glutathione Derivative with Chelating and in vitro Neuroprotective Activities: Synthesis, Physicochemical Properties, and Biological Evaluation. Chem Med Chem 8: 1818-1829.

24. Minelli A, Conte C, Cacciatore I, Cornacchia C, Pinnen F (2012) Molecular mechanism underlying the cerebral effect of Gly-Pro-Glu tripeptide bound to L-dopa in a Parkinson's animal model. Amino Acids 43: $1359-1367$.

25. Sozio P, Cerasa LS, Laserra S, Cacciatore I, Cornacchia C, et al. (2013) Memantine-sulfur containing antioxidant conjugates as potential prodrugs to improve the treatment of Alzheimer's disease. Eur J Pharm Sci 49: 187-198.

26. Pinnen F, Sozio P, Cacciatore I, Cornacchia C, Mollica A, et al. (2011) Ibuprofen and glutathione conjugate as a potential therapeutic agent for treating Alzheimer's disease. Arch Pharm (Weinheim) 344: 139-148.

27. Zara S, Di Stefano A, Nasuti C, Rapino M, Patruno A, et al. (2011) NOSmediated morphological and molecular modifications in rats infused with $\mathrm{AI}^{2}(1-40)$, as a model of Alzheimer's disease, in response to a new lipophilic molecular combination codrug-1. Exp Gerontol 46: 273-281.

28. Zara S, Rapino M, Sozio P, Di Stefano A, Nasuti C et al. (2011) Ibuprofen and lipoic acid codrug 1 control Alzheimer's disease progression by down-regulating protein kinase $\mathrm{C}$ e-mediated metalloproteinase 2 and 9 levels in $B$-amyloid infused Alzheimer's disease rat model. Brain Res 1412: 79-87.

29. Di Stefano A, Sozio P, Cerasa LS, Iannitelli A, Cataldi A et al. (2010) Ibuprofen and lipoic acid diamides as codrugs with neuroprotective activity: pharmacological properties and effects in beta-amyloid (1-40) infused Alzheimer's disease rat model. Int J Immunopathol Pharmacol 23: 589-599.

30. Frautschy SA, Horn DL, Sigel JJ, Harris-White ME, Mendoza JJ, et al. (1998) Protease inhibitor coinfusion with amyloid beta-protein results in enhanced deposition and toxicity in rat brain. J Neurosci 18: 8311-8321.

31. Smith MA, Rottkamp CA, Nunomura A, Raina AK, Perry G (2000) Oxidative stress in Alzheimer's disease. Biochim Biophys Acta 1502: 139-144.

32. Sharma M, Gupta YK (2003) Effect of alpha lipoic acid on intracerebroventricular streptozotocin model of cognitive impairment in rats. Eur Neuropsychopharmacol 13: 241-247.

33. Moreira PI, Santos MS, Oliveira CR, Shenk JC, Nunomura A, et al. (2008) Alzheimer disease and the role of free radicals in the pathogenesis of the disease. CNS Neurol Disord Drug Targets 7: 3-10.

34. Liu H, Wang H, Shenvi S, Hagen TM, Liu RM (2004) Glutathione metabolism during aging and in Alzheimer disease. Ann N Y Acad Sci 1019: 346-349.

35. Cacciatore I, Fornasari E, Baldassarre L, Cornacchia C, Fulle $\mathrm{S}$ et al. (2013) A potent (R)-alpha-bis-lipoyl derivative containing 8hydroxyquinoline scaffold: Synthesis and biological evaluation of its neuroprotective capabilities in SH-SY5Y human neuroblastoma cells. Pharmaceuticals 6: 54-69. 
Citation: Zara S, De Colli M, Sozio P, Cacciatore I, Bosco D (2014) Ibuprofen-Glutathione Conjugate as Anti-inflammatory and Anti-apoptotic Agent in Rat Brain Infused with $\beta$ Amyloid (1-40). J Cytol Histol 5: 249. doi:10.4172/2157-7099.1000249

Page 8 of 8

36. Sozio P, Marinelli L, Cacciatore I, Fontana A, Türkez H, et al. (2013) New flurbiprofen derivatives: synthesis, membrane affinity and evaluation of in vitro effect on $\hat{\mathrm{I}}^{2}$-amyloid levels. Molecules 18: 10747-10767.

37. Heneka MT, O'Banion MK (2007) Inflammatory processes in Alzheimer's disease. J Neuroimmunol 184: 69-91.

38. Nag E, Yee BK, Tang F (1999) Reduction in somatostatin and substance $P$ levels and choline acetyltransferase activity in the cortex and hippocampus of the rat after chronic intracerebroventricular infusion of beta-amyloid (1-40). Brain Res Bull 4: 251-262.

39. Strasser A1, O'Connor L, Dixit VM (2000) Apoptosis signaling. Annu Rev Biochem 69: 217-245.

40. Huang TC1, Lu KT, Wo YY, Wu YJ, Yang YL (2011) Resveratrol protects rats from $\mathrm{AI}^{2}$-induced neurotoxicity by the reduction of iNOS expression and lipid peroxidation. PLoS One 6: e29102.
41. Zhang H, Liu Y, Lao M, Ma Z, Yi X (2011) Puerarin protects Alzheimer's disease neuronal cybrids from oxidant-stress induced apoptosis by inhibiting pro-death signaling pathways. Exp Gerontol 46: 30-37.

42. Lamkanfi M, Kanneganti TD (2010) Caspase-7: a protease involved in apoptosis and inflammation. Int J Biochem Cell Biol 42: 21-24.

43. Manczak M, Mao P, Calkins MJ, Cornea A, Reddy AP, et al. (2010) Mitochondria-targeted antioxidants protect against amyloid-beta toxicity in Alzheimer's disease neurons. J Alzheimers Dis 20 Suppl 2: S609-631.

44. Reddy PH, Manczak M, Mao P, Calkins MJ, Reddy AP, et al. (2010) Amyloid-beta and mitochondria in aging and Alzheimer's disease: implications for synaptic damage and cognitive decline. J Alzheimers Dis 20 Suppl 2: S499-512. 